\title{
Covid 19 pandemic and its impact on children
}

\section{Chennadi Amith}

Professor and Head of Department of Paediatrics, Prathima Institue of Medical Sciences, Nagnur Road,Karimanagar

Corresponding Author : Dr. Chennadi Amith, Dept. of Paediatrics, Prathima Institue of Medical Sciences, Nagnur Road,Karimanagar

DOI: 10.47799/pimr.0803.01

(C) 2020-21 Prathima Institue of Medical Sciences

Introduction:

Covid-19, like on every other age group, showed a detrimental impact on children. We predicted more adversities among vulnerable lower socio economic groups but outcome is contrasting due to varied reasons. Despite minimal morbidity and mortality, There is a substantial impact on lifestyle, development, mental health and learning behaviour patterns in Paediatric population.

\section{Some of the positive impact ${ }^{1}$ :}

- Awareness regarding pandemic in detail is explained ,reassurances and practical measures to be taken to keep themselves and others safe.

- Spending quality time with children during the lockdown enabled closer relationship and bonding.

- Children had an opportunity to understand the value of nature and eco systems.

- Introduction of E learning helped the children to develop more creative skills and activities that would benefit them in later life keeping in pace with education.

\section{Some of negative impact:}

- Closing schools and library facilities which is only mode of education for some children who cannot access to internet impacted most in their learning. This is more seen in rural areas and lower socio economic background ${ }^{2}$.

- Anxiousness and frustration regarding reaching higher heights in their career and success is seen in children.

- Lack of outdoor physical activity which resulted in overeating and obesity.

- Nutritional deficiency is seen in children from rural and lower socio economic groups due to school closure who are dependent on government food programmes provided at school ${ }^{3}$.

- Isolation, physical distance, loneliness, fear of deprived of company and misunderstanding with their own peer groups are some challenging situations which brought drastic behavior changes in children ${ }^{4,5}$.

- There is a spike in child marriages mostly in lower socio economic groups.Child right crisis like child labour, child abuse, more so seen in lower socio economic classes.
- Addiction to social media and internet leading to cyber bullying and sexual exploitation.

\section{Conclusion:}

Long term impact on children are yet to be seen. Although some of these may be positive, but negative impacts may be devastating and could affect child development .There is a definite need for Government to work together with child welfare organizations and international health care organizations working for children to minimize the negative impact on children.

\section{REFERENCES}

1 UNESCO. Distance learning solutions. https://en.unesco.org/covid19/educationresponse/ solutions

2. UNICEF.How to talk to your child about coronavirus disease 2019 (COVID-19)

https://www.unicef.org/coronavirus/how-talk-yourchild-about-coronavirus-covid-19. Accessed March 11,2020

3. Van Lancker W, Parolin Z. COVID-19, school closures, and child poverty: a social crisis in the making. Lancet Public Health. 2020 May;5(5):e243-e244. doi: 10.1016/ S2468-2667(20)30084-0. Epub 2020 Apr 8. PMID: 32275858; PMCID: PMC7141480.

4. Chen P, Mao L, Nassis GP, Harmer P, Ainsworth BE, Li F. Coronavirus disease (COVID-19): The need to maintain regular physical activity while taking precautions. J Sport Health Sci. 2020 Mar;9(2):103-104. doi: 10.1016/ j.jshs.2020.02.001. Epub 2020 Feb 4. PMID: 32099716; PMCID: PMC7031771.

5. Beard JA, Bearden A, Striker R. Vitamin D and the antiviral state. J Clin Virol. 2011 Mar;50(3):194-200. doi: 10.1016/j.jcv.2010.12.006. Epub 2011 Jan 15. PMID: 21242105; PMCID: PMC3308600.

How to cite this article : Chennadi A. Covid 19 pandemic and its impact on children. Perspectives in Medical Research 2020; 8 (3):1

DOI: 10.47799/pimr.0803.01

Sources of Support: Nil, Conflict of interest: None declared 